\title{
PROCESSAMENTO DE CATALISADORES GASTOS DE UNIDADE DE HIDRODESSULFURIZAÇÃO PROFUNDA (ULTRA-DEEP HDS)
}

\author{
Carolina Leão Quintanilhaa, Júlio Carlos Afonso ${ }^{\mathrm{a}, *, \odot}$, Rubens Souza da Silva ${ }^{\mathrm{b}}$, Cláudio Augusto Vianna ${ }^{\mathrm{b}}$ e José Luiz \\ Mantovano ${ }^{\text {b }}$ \\ aDepartamento de Química Analítica, Instituto de Química, Universidade Federal do Rio de Janeiro, 21941-909 Rio de Janeiro \\ - RJ, Brasil \\ bDepartamento de Química e Materiais Nucleares, Instituto de Engenharia Nuclear, 21941-972 Rio de Janeiro - RJ, Brasil
}

Recebido em 07/03/2021; aceito em 12/07/2021; publicado na web em 03/08/2021

\begin{abstract}
PROCESSING OF SPENT ULTRA-DEEP HYDRODESULFURIZATION CATALYSTS. This work discusses the recycling of spent $\mathrm{NiMo} / \mathrm{Al}_{2} \mathrm{O}_{3}$ catalysts from ultra-deep hydrodesulfurization (HDS) units. They contain a refractory coke and fouling elements from the processed feedstocks. Samples were preoxidized $\left(600^{\circ} \mathrm{C}\right)$ for $12 \mathrm{~h}$ using a very slow heating rate to eliminate coke and volatiles. Experiments were performed in the presence of $\mathrm{HF}+\mathrm{H}_{2} \mathrm{O}_{2}$ mixtures under stirring at $25-60{ }^{\circ} \mathrm{C}$ for $1-4 \mathrm{~h}$. The amount of insoluble matter was the lowest (<1 wt.\% of the initial mass) after leaching for $2 \mathrm{~h}$ at $60{ }^{\circ} \mathrm{C}$ using an excess of $50 \mathrm{vol} . \% \mathrm{HF}$ and $20 \mathrm{vol} . \%$ $\mathrm{H}_{2} \mathrm{O}_{2}$. Leached molybdenum and vanadium were extracted together with Alamine 304 (tri-dodecylamine) in n-heptane at pH below 2. Aluminum and iron were precipitated from the raffinate as $\mathrm{Na}_{3} \mathrm{AlF}_{6}\left(+\mathrm{Na}_{3} \mathrm{FeF}_{6}\right)$ by adjusting pH at $\sim 4$ using $6 \mathrm{~mol} \mathrm{~L}^{-1} \mathrm{NaOH}$. Nickel was either recovered by solvent extraction using D2EHPA (bis-(2-ethylhexyl)phosphoric acid) in n-heptane at pH 6 or precipitated at $\mathrm{pH} 8$ using $6 \mathrm{~mol} \mathrm{~L}^{-1} \mathrm{NaOH}$. The first method proved better as less contaminants were present. After slow evaporation of the final aqueous solution, a mixture of $\mathrm{Na}_{2} \mathrm{SiF}_{6}$ and $\mathrm{NaF}$ was recovered. Fluoride losses were very low ( 0.10 wt.\%).
\end{abstract}

Keywords: spent catalysts; ultra-deep hydrodesulfurization; metals recovery; acidic leaching.

\section{INTRODUÇÃO}

Nos últimos anos, as refinarias vêm processado cargas mais pesadas devido a mudanças na qualidade do petróleo. A maximização do rendimento em produtos líquidos e o aproveitamento de resíduos vem merecendo atenção por parte dos refinadores. ${ }^{1}$ Hidroprocessamento é uma tecnologia-chave para a produção de combustíveis limpos devido às altas concentrações de enxofre, nitrogênio e metais, juntamente com um elevada proporção de precursores de coque em tais matérias-primas. ${ }^{2-6} \mathrm{~A}$ indústria de refino de petróleo consome grandes quantidades de catalisadores para purificar e refinar tais cargas por exigência de um nível de conversão elevado. ${ }^{6-8}$ Os catalisadores de hidroprocessamento são principalmente à base de NiMo, CoMo e NiW, depositados sobre alumina $\left(\mathrm{Al}_{2} \mathrm{O}_{3}\right),{ }^{8}$ geralmente modificada por inclusão de aditivos, os quais conferem uma melhor atividade em determinadas reações (hidrogenação e craqueamento) ou maior resistência térmica, ${ }^{9} \mathrm{e}$ trabalham na forma sulfetada. ${ }^{1,2} \mathrm{O}$ hidroprocessamento é uma das mais importantes aplicações da catálise. Seus catalisadores respondem por cerca de um terço do consumo mundial. ${ }^{10,11}$

Atualmente, as legislações ambientais impõem restrições severas em relação às emissões poluidoras $\left(\mathrm{NO}_{x}, \mathrm{SO}_{x}\right.$, entre outros) de refinarias e combustíveis. ${ }^{11,12} \mathrm{~A}$ hidrodessulfurização profunda (deep HDS) do diesel tornou-se uma questão importante nos últimos anos ${ }^{8}$ devido à regulamentação em vigor no país, que exige baixos níveis de enxofre $\left(<10 \mathrm{mg} \mathrm{kg}^{-1}\right)$ nesse combustível. ${ }^{9,13,14}$ Esses níveis só podem ser alcançados adotando condições mais severas de processamento do diesel bruto (aumento de temperatura, menor velocidade espacial e maior pressão parcial de hidrogênio), melhorando a eficiência dos processos existentes ${ }^{13}$ ou usando catalisadores mais ativos ${ }^{15} \mathrm{com}$ boa tolerância à desativação. ${ }^{3,13-16}$ Como resultado, a tecnologia atual de catalisadores de hidroprocessamento está levando a um

*e-mail: julio@iq.ufrj.br grande encurtamento de suas vidas úteis, ${ }^{6,8}$ e sua regenerabilidade e reciclagem se tornam cada vez mais difíceis. ${ }^{4}$

A desativação do catalisador desempenha um papel importante no projeto e nas operações das refinarias e na indústria petroquímica, tanto do ponto de vista econômico quanto tecnológico. ${ }^{1,2,17-20}$ Os catalisadores gastos de hidroprocessamento contribuem com uma quantidade significativa dos resíduos sólidos gerados pela indústria petroquímica e de refino de petróleo. ${ }^{6,21}$ A desativação se dá por deposição de coque, óleo e impurezas das cargas tratadas. ${ }^{22}$ Podem inflamar-se espontaneamente ao ar devido à presença de óleo e sulfetos metálicos. ${ }^{7}$ A Agência Norte-Americana de Proteção Ambiental (EPA) classificou o catalisador de hidroprocessamento gasto como um resíduo perigoso. ${ }^{12,19}$ Quanto mais pesada for a carga ${ }^{23}$ e maior o teor de contaminantes, mais rápida será a desativação do catalisador ${ }^{1,17}$ sob condições de reação severas, ${ }^{4,11}$ fenômeno crítico devido à tendência contínua de aumento da severidade do hidroprocessamento para atender às especificações de qualidade dos combustíveis. ${ }^{1,2,24}$ Para manter rendimentos e/ou qualidade constantes do produto, a perda de atividade catalítica deve ser compensada por aumentos periódicos da temperatura de reação. . $^{1,6,7,10}$

A deposição de coque no catalisador é geralmente considerada a principal causa de sua desativação. ${ }^{13,18,23,25,26}$ Ele é formado muito rapidamente nos estágios iniciais das reações de hidroprocessamento. ${ }^{1,27}$ Os poros do catalisador são fisicamente bloqueados, evitando a difusão dos reagentes pelos mesmos. ${ }^{25,26} \mathrm{~A}$ taxa de formação de coque aumenta com o aumento da temperatura de reação. ${ }^{26} \mathrm{~A}$ deposição de óleo também reduz a área superficial e o volume dos poros dos catalisadores com o tempo. ${ }^{22}$

A sinterização ou segregação da fase ativa, ${ }^{14,25,26,28-30}$ o envenenamento por deposição de compostos contendo nitrogênio e a deposição de elementos (silício, cálcio, ferro, arsênico etc.) ${ }^{13}$ também levam à perda de atividade. A presença de vanádio e níquel nas cargas brutas é de particular interesse. Esses metais são geralmente distribuídos entre estruturas do tipo porfirina e não porfirina. Eles se acumulam na 
forma de sulfetos na abertura dos poros do catalisador, ${ }^{27}$ bloqueando o acesso dos reagentes. ${ }^{26}$

Análises químicas em amostras desativadas submetidas a condições mais severas de HDS indicam a tendência à formação de um coque mais refratário (grafitizado), altamente susceptível à ignição $\mathrm{o}^{14,16,25,30} \mathrm{e}$, também, à maior deposição de elementos oriundos das cargas: As, Ca, V, Ni, Fe e Si. ${ }^{9,14,15,19,22,26,30,31}$

Gerenciar catalisadores gastos é um desafio para a indústria de refino no âmbito de sua gestão ambiental, o que estimula investimentos para o desenvolvimento de processos de reciclagem. , $2,7,25,28,32,33^{\text {Além }}$ das questões ambientais, existe uma preocupação em nível estratégico porque o teor de metais $(\mathrm{Ni}, \mathrm{Co}, \mathrm{Mo}, \mathrm{W}, \mathrm{Al})$ em catalisadores gastos normalmente supera a faixa encontrada em fontes naturais. ${ }^{6,34} \mathrm{O}$ catalisador gasto pode ser classificado como uma importante fonte secundária dos elementos supracitados. ${ }^{8,9,21,33,35,36}$

A remoção do coque e outras espécies voláteis contidas na superfície ${ }^{9,28,32}$ é um requisito para que se possa processar o catalisador gasto. ${ }^{8,36}$ É preciso cuidado para que a remoção desses depósitos (caracterizado por ser um processo exotérmico) não leve à ignição do catalisador, acarretando a formação de óxidos mistos de difícil solubilidade em meio aquoso. A solubilização da amostra deve ser feita empregando condições que reduzam o consumo de insumos e a geração de resíduos finais de processo..$^{33,37}$

Em um estudo detalhado feito em nosso grupo de pesquisa, ${ }^{38}$ com catalisadores gastos de unidade de ultra-deep HDS, constatouse que o coque era de natureza aromática, com uma baixa razão atômica $\mathrm{H} / \mathrm{C}(<1,2)$ e alta proporção de carbono $\mathrm{sp}^{2}$. Além disso, foram identificados diversos elementos oriundos das cargas tratadas, aumentando a complexidade do catalisador gasto em termos de composição elementar. A lixiviação desses catalisadores com ácido sulfúrico nas condições aplicadas a catalisadores oriundos de unidades de HDS convencionais ${ }^{9}$ resultou em níveis muito baixos de solubilização da fase ativa (Ni e Mo) e do suporte (Al), sendo atribuído à ignição do coque sob as condições de oxidação aplicadas às amostras mais antigas e à presença de elementos oriundos das cargas..$^{38}$ Assim, é necessário reestudar os parâmetros de queima de coque e avaliar o processamento hidrometalúrgico com um ácido capaz de dissolver os compostos refratários formados pela ignição do coque.

A literatura aponta que processos hidrometalúrgicos em meio ácido são as principais rotas usadas para processar catalisadores gastos de hidroprocessamento devido à alta dissolução dos metais. ${ }^{9,36}$ O ácido sulfúrico é o lixiviante mais citado. ${ }^{9,22,37}$ Processos envolvendo fusão alcalina ou digestão com $\mathrm{KOH}_{\text {aq. }}$ ou $\mathrm{NaOH}_{\text {aq. }}$ são citados para recuperar de forma seletiva molibdênio (ou tungstênio), vanádio e alumínio..$^{21,39,40}$ ou ainda amônia e sais de amônio para lixiviar molibdênio, vanádio e níquel (ou cobalto). ${ }^{41,42}$

Dada a natureza multicomponente desse resíduo, é necessária uma combinação de técnicas para isolamento dos elementos lixiviados. Os principais métodos envolvem adsorção, quelação, troca iônica, precipitação e extração por solvente. ${ }^{21,36}$ As duas últimas são as mais citadas. ${ }^{21} \mathrm{~A}$ desvantagem da precipitação está na dificuldade de isolar produtos com pureza adequada. ${ }^{36} \mathrm{~A}$ extração por solvente é efetiva para isolar molibdênio e vanádio em $\mathrm{pH}$ abaixo de 2, sendo rextraídos por soluções aquosas amoniacais, ${ }^{43,44}$ situação em que o vanádio pode ser precipitado como metavanadato $\left(\mathrm{NH}_{4} \mathrm{VO}_{3}\right)$ em pH neutro a levemente alcalino. ${ }^{41} \mathrm{~A}$ adsorção e a complexação com agentes quelantes oferecem meios úteis para a recuperação seletiva de metais, embora a escala de sua aplicação na indústria ainda seja limitada. ${ }^{21} \mathrm{~A}$ troca iônica é adequada para a purificação de íons metálicos. ${ }^{36}$

O presente trabalho consistiu em desenvolver um processo hidrometalúrgico aplicável a catalisadores gastos de unidades de ultra-deep HDS. ${ }^{38}$ Foi estudada a influência de parâmetros operacionais na delicada etapa de remoção do coque. As amostras pré-oxidadas foram submetidas à lixiviação com uma mistura de ácido fluorídrico com peróxido de hidrogênio, já aplicada com sucesso na lixiviação de catalisadores de hidroprocessamento contendo silício. ${ }^{45}$ Os lixiviados foram submetidos a um processo de fracionamento envolvendo extração por solvente e precipitação, os métodos mais usados na literatura, e o fluoreto presente na solução aquosa final foi recuperado por cristalização de seu sal de sódio.

\section{PARTE EXPERIMENTAL}

\section{Catalisadores}

Duas amostras de catalisadores $\mathrm{NiMo} / \mathrm{Al}_{2} \mathrm{O}_{3}$ (extrudados cilíndricos de $5 \mathrm{~mm}$ de comprimento e $1,2 \mathrm{~mm}$ de diâmetro) foram usados neste estudo. Esses catalisadores foram empregados na forma sulfetada em uma unidade de hidrodessulfurização profunda (ultra-deep HDS) de frações diesel de uma refinaria brasileira no período 2008-2011. As características das cargas tratadas e um sumário das condições operacionais são apresentadas em trabalho anterior. $^{38}$

Após a remoção do reator, a carga residual e outros materiais aderidos à superfície foram removidos do catalisador por extração em soxhlet com tolueno por $12 \mathrm{~h}$. O catalisador foi seco a $110^{\circ} \mathrm{C}$ por $2 \mathrm{~h}$ sob fluxo de $\mathrm{N}_{2}$ seco, ${ }^{16,17,46}$ sendo armazenado sob $\mathrm{N}_{2}$ no escuro a $25^{\circ} \mathrm{C}$.

Dados de análise elementar $(\mathrm{CHN})$ fornecidos pela refinaria indicam um teor de coque de $8,8 \% \mathrm{~m} / \mathrm{m}$ no catalisador 1 e $9,7 \%$ $\mathrm{m} / \mathrm{m}$ no catalisador 2 , e uma razão atômica $\mathrm{H} / \mathrm{C}$ da ordem de 1,17 para ambas as amostras. $\mathrm{O}$ teor de enxofre nos catalisadores desativados (analisador LECO) é $18 \% \mathrm{~m} / \mathrm{m}$ (catalisador 1) e $22,5 \%$ $\mathrm{m} / \mathrm{m}$ (catalisador 2).

\section{Reagentes}

Ácido bis-2-etil-hexilfosfórico (D2EHPA, Sigma-Aldrich) $98 \%$ $\mathrm{m} / \mathrm{m}$ e tridodecilamina (Alamina 304, BASF) $95 \% \mathrm{~m} / \mathrm{m}$ foram empregados como extratantes. n-Heptano (Merck) foi usado como diluente. Ácido fluorídrico (Merck, 40\% m/m, $20 \mathrm{~mol} \mathrm{~L}^{-1}$ ), ácido sulfúrico (Merck, $98 \% \mathrm{~m} / \mathrm{m}, \sim 18 \mathrm{~mol} \mathrm{~L}^{-1}$ ), amônia aquosa (SigmaAldrich, $28 \% \mathrm{~m} / \mathrm{m}, \sim 15 \mathrm{~mol} \mathrm{~L}^{-1}$ ), ácido clorídrico (Merck, $37 \% \mathrm{~m} / \mathrm{m}$, $\sim 12 \mathrm{~mol} \mathrm{~L}^{-1}$ ), peróxido de hidrogênio (Merck, 30\% m/m, $\sim 8,8 \mathrm{mil} \mathrm{L}^{-1}$ ) e hidróxido de sódio (Merck) foram de grau analítico. As soluções foram preparadas com água destilada.

\section{Remoção do coque}

Considerando a criticalidade desta etapa para o sucesso do processo de lixiviação ácida, foram usados dois procedimentos nos quais a diferença básica é a temperatura final de aquecimento, 500 ou $600{ }^{\circ} \mathrm{C}$. Ambos os experimentos foram executados em triplicata.

No procedimento 1, a amostra de catalisador, previamente pesada em balança analítica, foi colocada em cápsula de porcelana. Com não foi previamente macerada, a altura da camada de catalisador foi mantida abaixo de $0,5 \mathrm{~cm}$ para garantir um tratamento uniforme de toda a amostra. A cápsula foi inserida em uma mufla pré-aquecida a $250{ }^{\circ} \mathrm{C}$, permanecendo por $1 \mathrm{~h}$ nessa temperatura. A partir daí a amostra foi aquecida a uma velocidade de $0,5{ }^{\circ} \mathrm{C} \mathrm{min}^{-1}$, até a temperatura final de $500^{\circ} \mathrm{C}$, permanecendo neste patamar por $1 \mathrm{~h}$. No procedimento 2 , a amostra, após permanecer na mufla a $250{ }^{\circ} \mathrm{C}$ por $1 \mathrm{~h}$, foi aquecida até $600{ }^{\circ} \mathrm{C}$ sob a mesma taxa de aquecimento $\left(0,5^{\circ} \mathrm{C} \mathrm{min}^{-1}\right)$. Ao final do experimento, a amostra foi resfriada na própria mufla até $25^{\circ} \mathrm{C}$, pesada em balança analítica, e transferida para dessecador. 


\section{Lixiviação ácida das amostras pré-oxidadas}

Em função da possibilidade de formação de fases mistas por meio de reações entre os elementos presentes nos catalisadores, com base na literatura, ${ }^{1,47}$ foram usadas misturas de ácido fluorídrico $40 \% \mathrm{~m} / \mathrm{m}$ ( $\left.20 \mathrm{~mol} \mathrm{~L}^{-1}\right)$ e peróxido de hidrogênio $30 \% \mathrm{~m} / \mathrm{m}\left(\sim 8,8 \mathrm{~mol} \mathrm{~L}^{-1}\right)$. Elas se mostraram efetivas na solubilização de catalisadores NiMo e $\mathrm{CoMo} / \mathrm{Al}_{2} \mathrm{O}_{3}$ contendo silício adicionado ao suporte. A premissa é aproveitar as propriedades complexantes do íon fluoreto sobre o alumínio, ${ }^{48,49}$ formando o íon $\left[\mathrm{AlF}_{6}\right]^{3-}$, e do peróxido sobre o molibdênio hexavalente e o vanádio pentavalente, com formação de peroximolibdatos e peroxivanadatos, de coloração vermelha e facilmente distinguidos no meio reacional. ${ }^{48,49}$ Essas misturas foram manipuladas com os equipamentos de proteção individual apropriados (óculos de segurança com proteção contra respingos, protetor facial, luvas de neoprene e jaleco de algodão). Todos os experimentos foram executados em béqueres de teflon e em capela com exaustão. Com base na composição química das amostras de catalisadores préoxidados e nas reações a seguir:

$$
\begin{gathered}
\mathrm{XO}+2 \mathrm{HF} \rightarrow \mathrm{XF}_{2}+\mathrm{H}_{2} \mathrm{O}(\mathrm{X}=\mathrm{Mn}, \mathrm{Ni}, \mathrm{Cu}, \mathrm{Zn}) \\
\mathrm{MoO}_{3}+2 \mathrm{HF} \rightarrow \mathrm{MoO}_{2}^{+}+2 \mathrm{~F}^{-}+\mathrm{H}_{2} \mathrm{O} \\
\mathrm{Al}_{2} \mathrm{O}_{3}+12 \mathrm{HF} \rightarrow 2\left[\mathrm{AlF}_{6}\right]^{3-}+6 \mathrm{H}^{+}+3 \mathrm{H}_{2} \mathrm{O} \\
\mathrm{Fe}_{2} \mathrm{O}_{3}+12 \mathrm{HF} \rightarrow 2\left[\mathrm{FeF}_{6}\right]^{3-}+6 \mathrm{H}^{+}+3 \mathrm{H}_{2} \mathrm{O} \\
\mathrm{Cr}_{2} \mathrm{O}_{3}+12 \mathrm{HF} \rightarrow 2\left[\mathrm{CrF}_{6}\right]^{3-}+6 \mathrm{H}^{+}+3 \mathrm{H}_{2} \mathrm{O} \\
\mathrm{SiO}_{2}+6 \mathrm{HF} \rightarrow\left[\mathrm{SiF}_{6}\right]^{2-}+2 \mathrm{H}^{+}+4 \mathrm{H}_{2} \mathrm{O} \\
\mathrm{CaO}+2 \mathrm{HF} \rightarrow \mathrm{CaF}_{2} \downarrow+\mathrm{H}_{2} \mathrm{O} \\
\mathrm{V}_{2} \mathrm{O}_{5}+2 \mathrm{HF} \rightarrow 2 \mathrm{VO}_{2}^{+}+2 \mathrm{~F}^{-}+\mathrm{H}_{2} \mathrm{O}
\end{gathered}
$$

calculou-se a quantidade de $\mathrm{HF} 40 \% \mathrm{~m} / \mathrm{m}$ necessário para reagir com os óxidos supracitados. Além da quantidade estequiométrica, empregou-se excesso de HF nas proporções de 10 até $50 \%$ em volume.

No caso do peróxido de hidrogênio a $30 \% \mathrm{~m} / \mathrm{m}$, as reações previstas são: $:^{50,51}$

$$
\begin{aligned}
& \mathrm{MoO}_{3}+2 \mathrm{HF}+\mathrm{H}_{2} \mathrm{O}_{2} \rightarrow \mathrm{MoO}_{3}^{2+}+2 \mathrm{~F}^{-}+2 \mathrm{H}_{2} \mathrm{O} \\
& \mathrm{V}_{2} \mathrm{O}_{5}+6 \mathrm{HF}+2 \mathrm{H}_{2} \mathrm{O}_{2} \rightarrow 2 \mathrm{VO}_{2}{ }^{3+}+6 \mathrm{~F}^{-}+5 \mathrm{H}_{2} \mathrm{O}
\end{aligned}
$$

Empregou-se um excesso de $20 \%$ vol. em relação ao teórico em todos os experimentos.

Conhecendo os riscos referentes ao ácido fluorídrico, o procedimento experimental aplicado foi ligeiramente diferente em relação àquele usado na literatura. ${ }^{47} \mathrm{~A}$ temperatura foi variada de 25 até $60^{\circ} \mathrm{C}$, controlada por um termômetro, e o tempo de digestão foi variado até $4 \mathrm{~h}$. A massa de catalisador nos experimentos foi fixada em $10 \mathrm{~g}, \mathrm{e}$ a agitação foi fixada em $250 \mathrm{rpm}$. A cor inicial do meio reacional era vermelho-alaranjada devido aos peroxicomplexos de $\mathrm{Mo}(\mathrm{VI})$ e $\mathrm{V}(\mathrm{V})$, mas ao final do experimento a cor era verde devido aos íons $\mathrm{Ni}(\mathrm{II})$.

Para fins de comparação, experimentos apenas com HF (na quantidade estequiométrica) ou $\mathrm{H}_{2} \mathrm{O}_{2}$ foram realizados. A solução ausente na mistura foi substituída por água destilada para manter a mesma relação entre a massa de sódio $(10 \mathrm{~g})$ e o volume total de solução.

Após a lixiviação, o resíduo insolúvel foi separado por filtração em papel quantitativo de filtração média. O sólido foi lavado três vezes com água destilada $\left(3 \mathrm{~mL} \mathrm{~g}^{-1}\right)$ e as águas de lavagem foram adicionadas ao lixiviado. O sólido lavado foi seco a $25{ }^{\circ} \mathrm{C}$ em dessecador e depois pesado.

\section{Processamento do lixiviado}

O procedimento de separação empregado baseou-se numa conbinação de técnicas de precipitação e extração por solvente conduzidas sob elevação progressiva do pH e evaporação da solução final para recuperação do íon fluoreto. A Figura 1 apresenta o esquema geral para a separação dos elementos dos lixiviados.

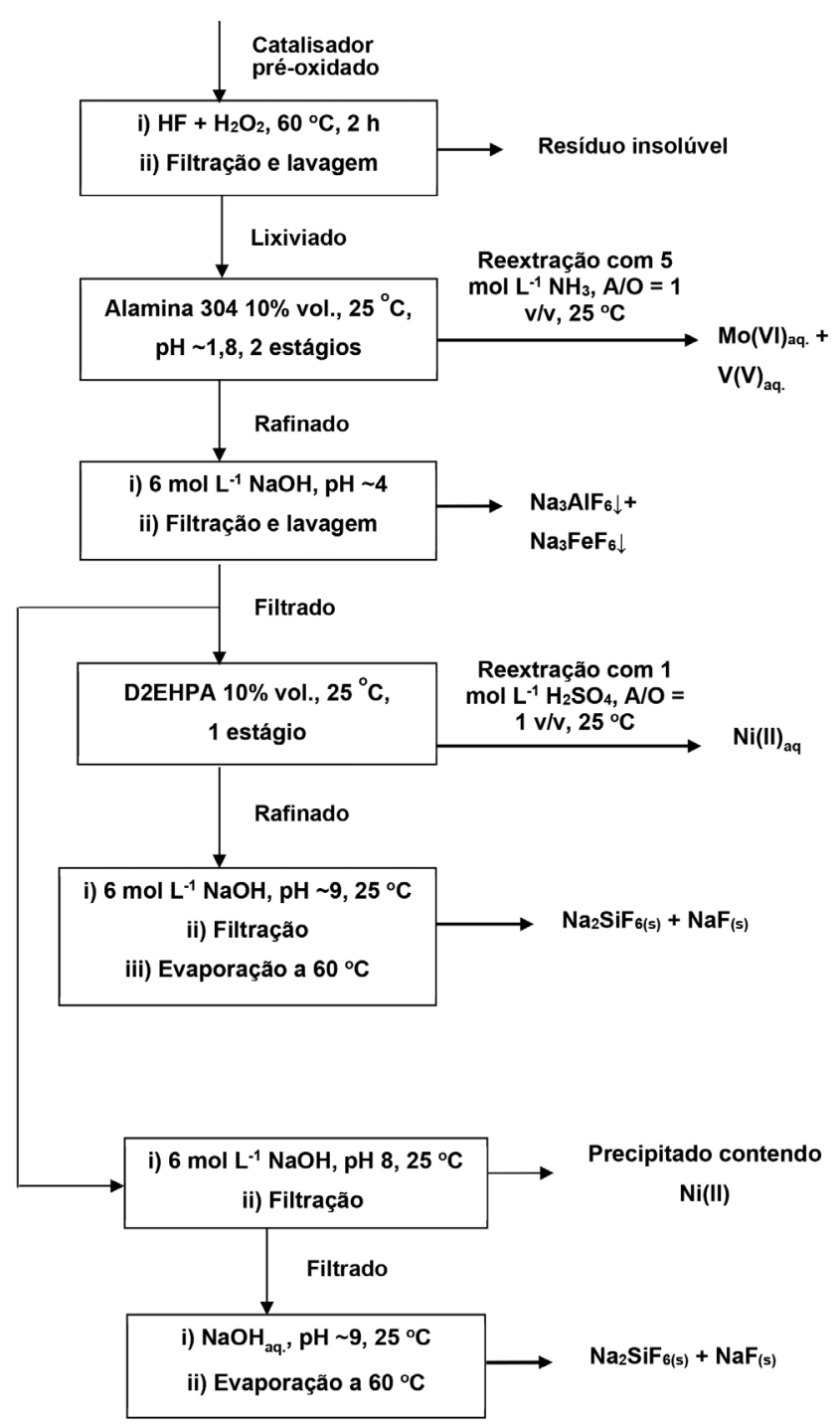

Figura 1. Fluxograma de processamento do lixiviado após abertura dos catalisadores com misturas $\mathrm{HF}+\mathrm{H}_{2} \mathrm{O}_{2}$

Extração líquido-líquido de $M o(V I)$ e V(V)

Os experimentos foram realizados em funis de separação de plástico a $25^{\circ} \mathrm{C}$. O extratante usado foi a Alamina 304, tridodecilamina, concebida para remover o molibdênio de soluções aquosas ácidas. ${ }^{52}$ Esse extratante pode também extrair $\mathrm{V}(\mathrm{V})$ de soluções com pH abaixo de $2 .{ }^{41,53}$ A concentração em n-heptano variou de 5 a $30 \%$ em volume. A proporção entre as fases aquosa e $\operatorname{orgânica~(A/O)~foi~fixada~em~} 1$ vol./vol. O pH do lixiviado foi ajustado a 1,8 pela adição da quantidade apropriada de $\mathrm{NaOH} 6 \mathrm{~mol} \mathrm{~L}^{-1}$. $\mathrm{O}$ sistema foi agitado durante $10 \mathrm{~min}$. A separação de fases foi alcançada em $\sim 10 \mathrm{~min}$. Os experimentos foram realizados em triplicata e o erro experimental incluindo o erro analítico foi de $4 \%$ a um nível de confiança de $95 \%$. A quantidade de elemento extraído foi calculada pela diferença entre as concentrações no rafinado e no lixiviado original. A fase orgânica apresentava cor amarela, devido aos oxocátions $\mathrm{MoO}_{2}{ }^{2+}$ e $\mathrm{VO}_{2}{ }^{+}$, enquanto a fase aquosa (rafinado) tinha cor verde devido ao íon $\mathrm{Ni}^{2+}$.

A reextração foi conduzida a $25^{\circ} \mathrm{C}$ usando solução de amônia (1 a $\left.6 \mathrm{~mol} \mathrm{~L}^{-1}\right)$ em funis de separação de plástico. A razão entre as fases 
fase aquosa e orgânica foi fixada em $1 \mathrm{vol} / \mathrm{vol}$. O sistema foi agitado durante $10 \mathrm{~min}$. A separação de fases foi alcançada em $10 \mathrm{~min}$. A partir da solução aquosa amoniacal o $\mathrm{pH}$ foi ajustado a 7 mediante adição de $\mathrm{HCl} 0,1 \mathrm{~mol} \mathrm{~L}^{-1}$. Um precipitado branco, em pequena quantidade, foi formado, sendo separado por centrifugação.

Os experimentos foram realizados em triplicata e o erro experimental incluindo o erro analítico foi de $3 \%$ a um nível de confiança de $95 \%$.

\section{Precipitação do $\mathrm{Fe}(I I I)$ e do Al(III)}

Os experimentos foram conduzidos em béqueres de teflon a $25^{\circ} \mathrm{C}$ sob agitação (200 rpm), segundo o procedimento descrito na literatura. ${ }^{54} \mathrm{O}$ pH do rafinado após a extração de $\mathrm{Mo}(\mathrm{VI})$ e $\mathrm{V}(\mathrm{V})$ foi ajustado a 4 mediante adição lenta de solução de $\mathrm{NaOH} 6 \mathrm{~mol} \mathrm{~L}^{-1}$ $\left(\sim 1 \mathrm{~mL} \mathrm{~min}^{-1}\right)$ para evitar uma subida brusca do $\mathrm{pH} .{ }^{47}$ Obteve-se um sólido branco finamente dividido, que foi filtrado e lavado com HF diluído $\left(0,01 \mathrm{~mol} \mathrm{~L}^{-1}\right)$ e água $\left(2 \mathrm{~mL} \mathrm{~g}^{-1}\right)$. Foi seco em estufa a $110^{\circ} \mathrm{C}$ por $2 \mathrm{~h}$ e resfriado em dessecador.

\section{Isolamento do $\mathrm{Ni}(\mathrm{II})$}

Após a precipitação do alumínio e do ferro, duas rotas distintas foram empregadas:

- a solução foi tratada com $\mathrm{NaOH} 6 \mathrm{~mol} \mathrm{~L}^{-1}$ a $25^{\circ} \mathrm{C}$ sob agitação (200 rpm) até $\mathrm{pH} 8 .{ }^{33}$ Formou-se um precipitado verde, o qual foi filtrado e lavado com $\mathrm{NaOH} 0,01 \mathrm{~mol} \mathrm{~L}^{-1} \mathrm{e}$ água $\left(3 \mathrm{~mL} \mathrm{~g}^{-1}\right)$, seco em estufa a $110^{\circ} \mathrm{C}$ por $2 \mathrm{~h}$, resfriado em dessecador e pesado. o pH da solução foi ajustado a 6 mediante adição de $\mathrm{NaOH}$ $6 \mathrm{~mol} \mathrm{~L}{ }^{-1}$ a $25{ }^{\circ} \mathrm{C}$ sob agitação (200 rpm). Ácido bis-2-etil-hexilfosfórico (D2EHPA) foi usado como extratante (5-20 vol.\%), diluído em n-heptano. ${ }^{54} \mathrm{~A}$ proporção entre as fases aquosa e orgânica (A/O) foi fixada em 1 vol./vol. O sistema foi agitado durante $10 \mathrm{~min}$. A separação de fases foi alcançada em $~ 10 \mathrm{~min}$. Os experimentos foram realizados em triplicata e o erro experimental incluindo o erro analítico foi de $3 \%$ a um nível de confiança de $95 \%$. A reextração foi conduzida a $25^{\circ} \mathrm{C}$ usando solução de $\mathrm{H}_{2} \mathrm{SO}_{4}$ (1 a $6 \mathrm{~mol} \mathrm{~L}^{-1}$ ) em funis de separação de plástico. ${ }^{54} \mathrm{~A}$ razão entre as fases fase aquosa e orgânica foi fixada em $1 \mathrm{vol} / \mathrm{vol}$. O sistema foi agitado durante $10 \mathrm{~min}$. A separação de fases foi alcançada em $\sim 8$ min.

\section{Isolamento do fluoreto de sódio}

Após a separação do níquel, a solução final, incolor, teve seu pH ajustado até 9 por meio de adição de solução de $\mathrm{NaOH} 6 \mathrm{~mol} \mathrm{~L}^{-1}$. Esse $\mathrm{pH}$ foi escolhido porque corresponde àquele de uma solução saturada de $\mathrm{NaF}\left(\sim 42 \mathrm{~g} \mathrm{~L}^{-1}\right.$ a $\left.25^{\circ} \mathrm{C}\right) \cdot{ }^{47,48}$ No caso dos experimentos de extração do $\mathrm{Ni}$ (II) em $\mathrm{pH}$ 6, formou-se um precipitado, o qual foi separado por filtração e lavado com água $\left(2 \mathrm{ml} \mathrm{g}^{-1}\right)$. Em seguida, a solução foi colocada para evaporar em placa de aquecimento na capela, a $60{ }^{\circ} \mathrm{C}$, com o objetivo de isolar o sal supracitado. O sólido obtido, branco, foi pesado em balança analítica e conservado em dessecador.

\section{Métodos analíticos}

Os catalisadores pré-oxidados e os sólidos obtidos durante o processamento do lixiviado foram pesados em balança analítica (Scientech SA 120) e analisados por fluorescência de raios X (FRX) por energia dispersiva em um equipamento Shimadzu EDX $800 \mathrm{HS}$ com tubo de raios $\mathrm{x}$ de ródio e detector de $\mathrm{Si}(\mathrm{Li})$. A voltagem do tubo de raios $\mathrm{x}$ foi $50 \mathrm{kV}$ e a corrente foi $1 \mathrm{~mA}$. As amostras foram irradiadas por $100 \mathrm{~s}$. Os espectros foram adquiridos sequencialmente de 0 a $40 \mathrm{keV}$ com etapas de $0,5 \mathrm{keV}$. A quantificação dos elementos foi realizada pelo método dos parâmetros fundamentais (FP) com o software DXP-700E versão 1.00 rel. $014 .{ }^{55} \mathrm{O}$ limite de detecção foi da ordem de $1 \mathrm{mg} \mathrm{kg}^{-1}$. As amostras foram prensadas com ácido bórico $\left(\mathrm{H}_{3} \mathrm{BO}_{3}\right)$ (proporção em massa de 1:4).

As fases cristalinas nas amostras sólidas foram identificadas por difração de raios-X (XRD, Shimadzu XRD 6000) pelo método de varredura contínua a $20 \mathrm{~mA}$ e $40 \mathrm{kV}$, usando $\mathrm{Cu} \mathrm{K} \alpha(\lambda=0,15418)$ como fonte de radiação. O ângulo de difração $(2 \theta)$ foi registrado de $10^{\circ}$ a $70^{\circ}$ a uma taxa de varredura de $3^{\circ} \mathrm{min}^{-1}$. Como referência, foi usado um banco de dados de difratogramas (PDF2, 2013) do ICDD (International Centre for Diffraction Data).

As concentrações de íons metálicos em solução aquosa foram determinadas por espectometria de absorção atômica (Perkin Elmer AAS 3300) sob as seguintes condições operacionais: vazão de ar, $8 \mathrm{~L} \mathrm{~min}^{-1}$; vazão de acetileno, $2 \mathrm{~L} \mathrm{~min}^{-1}$; vazão de amostra, $6 \mathrm{~mL} \mathrm{~min}{ }^{-1}$; tempo de medida, $4 \mathrm{~s}$. Os seguintes comprimentos de onda foram empregados: zinco, 213,9 nm; ferro, 248,3 nm; níquel, 232,2 nm; alumínio, 396,2 nm; cobre, 224,4 nm; silício, 251,6 nm; molibdênio, $320,9 \mathrm{~nm}$; vanádio, $318,5 \mathrm{~nm}$; cálcio, $422,7 \mathrm{~nm}$; cromo, 357,9 nm; manganês, $279,5 \mathrm{~nm}$. Os limites de detecção e quantificação foram determinados experimentalmente, sendo, respectivamente: $10 \mathrm{e}$ $50 \mu \mathrm{g} \mathrm{L}^{-1}$ (V, Fe, Cr); 5 e $20 \mu \mathrm{g} \mathrm{L}^{-1}$ (Mn, Zn, Cu, Ca e Ni); 5 e $15 \mu \mathrm{g} \mathrm{L} \mathrm{L}^{-1}$ (Mo); $100 \mathrm{e} 400 \mu \mathrm{g} \mathrm{L}^{-1}$ (Al, Si). O pH de soluções aquosas foi medido com um eletrodo de vidro combinado a um de $\mathrm{Ag} / \mathrm{AgCl}$ (Orion 2AI3-JG). As análises foram realizadas em triplicata e o erro analítico foi de $3 \%$ a um nível de confiança de $95 \%$.

\section{RESULTADOS E DISCUSSÃO}

\section{Composição dos catalisadores}

Os dados de composição elementar dos catalisadores após a queima do coque são reportados na Tabela 1. Chamam a atenção os elevados teores de molibdênio e níquel, componentes da fase ativa. É uma estratégia para aumentar a atividade dos catalisadores em condições de ultra-deep HDS. ${ }^{34,37}$ Os elevados teores de enxofre nas amostras originais $(18,0$ e $22,5 \% \mathrm{~m} / \mathrm{m})$ e pré-oxidadas (Tabela 1) estão em consonância com a maior quantidade de fase ativa porque o catalisador trabalhou na forma sulfetada na unidade de HDS. A presença de $\mathrm{P}$ e $\mathrm{Si}$ adicionados ao suporte ${ }^{38}$ é outra estratégia para aumentar a atividade em HDS por regulação da acidez do suporte. ${ }^{34,35,37}$ Com base nos dados dessa tabela é que se estabeleceram

Tabela 1. Composição* $(\% \mathrm{~m} / \mathrm{m})$ de catalisadores $\mathrm{NiMo} / \mathrm{Al}_{2} \mathrm{O}_{3}$ desativados retirados de unidade de hidrodessulfurização profunda (ultra-deep HDS)

\begin{tabular}{lcc}
\hline Elemento (como óxido) & Catalisador 1 & Catalisador 2 \\
\hline $\mathrm{Al}_{2} \mathrm{O}_{3}$ & 52,9 & 43,2 \\
$\mathrm{MoO}_{3}$ & 21,4 & 21,2 \\
$\mathrm{SO}_{3}$ & 12,2 & 15,1 \\
$\mathrm{SiO}_{2}$ & 5,6 & 9,4 \\
$\mathrm{NiO}$ & 4,0 & 4,5 \\
$\mathrm{P}_{2} \mathrm{O}_{5}$ & 1,7 & 2,6 \\
$\mathrm{Fe}_{2} \mathrm{O}_{3}$ & 1,6 & 3,1 \\
$\mathrm{CaO}$ & 0,4 & 0,4 \\
$\mathrm{As}_{2} \mathrm{O}_{5}$ & 0,2 & 0,2 \\
$\mathrm{~V}_{2} \mathrm{O}_{5}$ & 0,1 & 0,3 \\
$\mathrm{Cr}_{2} \mathrm{O}_{3}$ & $4,0 \times 10^{-2}$ & $4,0 \times 10^{-2}$ \\
$\mathrm{CuO}$ & Não detectado & $4,0 \times 10^{-2}$ \\
$\mathrm{MnO}$ & $3,0 \times 10^{-2}$ & $3,0 \times 10^{-2}$ \\
$\mathrm{ZnO}$ & $6,0 \times 10^{-3}$ & Não detectado \\
\hline
\end{tabular}

*Em base seca e após remoção do coque. 
as quantidades estequiométricas de $\mathrm{HF}$ e de $\mathrm{H}_{2} \mathrm{O}_{2}$ para a lixiviação das amostras (reações 1 a 10). Isso corresponde a um volume de $\mathrm{HF}$ $40 \% \mathrm{~m} / \mathrm{m}$ igual a $3860 \mathrm{~mL} \mathrm{~kg}^{-1}$ de catalisador 1 e $3530 \mathrm{~mL} \mathrm{~kg}^{-1} \mathrm{de}$ catalisador 2. O volume estimado referente ao $\mathrm{H}_{2} \mathrm{O}_{2}(30 \% \mathrm{~m} / \mathrm{m})$ é $170 \mathrm{~mL} \mathrm{~kg}^{-1}$ para ambos os catalisadores.

\section{Eliminação do coque}

A Tabela 2 apresenta os dados de perda de massa dos catalisadores após a eliminação do coque. O procedimento 2 levou a uma maior perda de massa em comparação ao procedimento 1, aproximadamente $19 \%$ a mais para o catalisador 1 e $12 \%$ para o catalisador 2 . As perdas de massa mais elevadas para o catalisador 2 se explicam pelos maiores teores de carbono e enxofre nesta amostra, eliminados como $\mathrm{CO}_{2} \mathrm{e}$ $\mathrm{SO}_{2}$, respectivamente. $\mathrm{O}$ aspecto das amostras sugere que nem todo o coque foi removido a $500{ }^{\circ} \mathrm{C}$ (Figura 2 ). A cor original do catalisador (verde) não foi restaurada nem mesmo nas amostras oxidadas a $600{ }^{\circ} \mathrm{C}$ devido ao ferro depositado sobre a superfície. Dado que o coque das amostras em estudo apresenta uma razão atômica $\mathrm{H} / \mathrm{C}$ inferior a 1,2 , ele exige temperaturas mais elevadas para ser eliminado por ser refratário (alto teor de carbonos aromáticos). ${ }^{38} \mathrm{As}$ amostras oxidadas, mesmo a $600{ }^{\circ} \mathrm{C}$, apresentam baixa cristalinidade com base nos difratogramas de raios x (Figura 3).

Tabela 2. Dados de perda de massa das amostras após queima do coque a 500 ou $600^{\circ} \mathrm{C}$

\begin{tabular}{lcc}
\hline Amostra & Perda a $500{ }^{\circ} \mathrm{C}$ & Perda a $600{ }^{\circ} \mathrm{C}$ \\
\hline 1 & $19,6 \pm 0,2$ & $23,4 \pm 0,5$ \\
2 & $29,5 \pm 0,5$ & $34,5 \pm 0,1$ \\
\hline
\end{tabular}

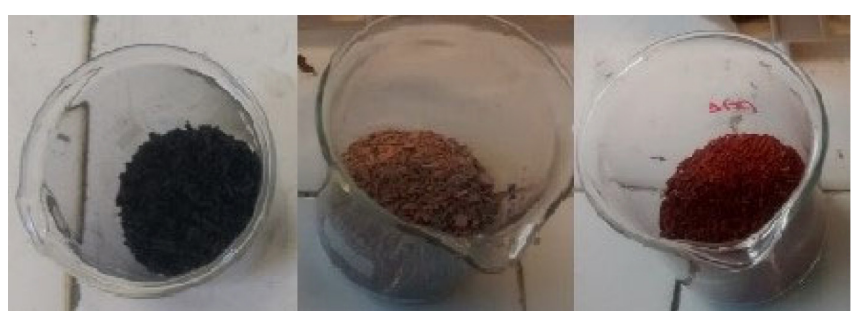

Figura 2. Aspecto de uma amostra de catalisador $\mathrm{NiMo} / \mathrm{Al}_{2} \mathrm{O}_{3}$ desativado (esquerda) após oxidação do coque a $500^{\circ} \mathrm{C}$ (centro) e $600^{\circ} \mathrm{C}$ (direita)
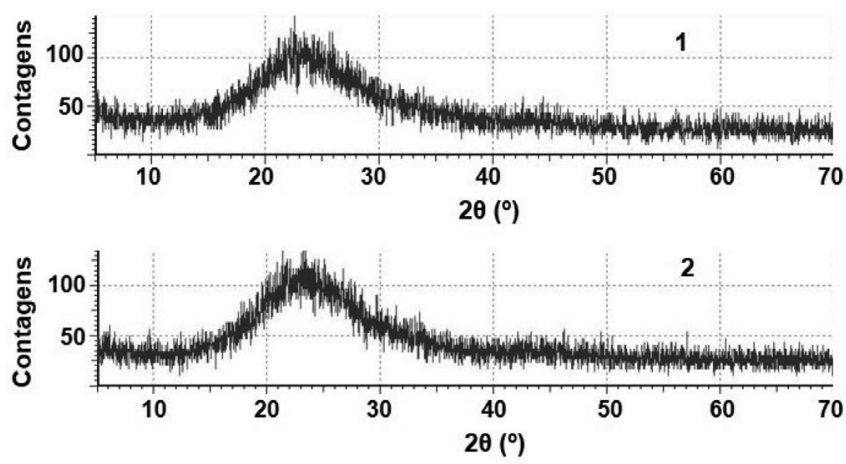

Figura 3. Difratogramas dos catalisadores 1 e 2 após oxidação do coque a $600{ }^{\circ} \mathrm{C}$

\section{Lixiviação das amostras pré-oxidadas}

A Tabela 3 mostra o percentual relativo de resíduo insolúvel recuperado nos diversos experimentos, após $3 \mathrm{~h}$ a $60^{\circ} \mathrm{C}$. Percebe-se a importância do peróxido de hidrogênio como correagente visto que a lixiviação foi mínima na presença de HF sozinho. Da mesma forma, a lixiviação com $\mathrm{H}_{2} \mathrm{O}_{2}$ isoladamente não foi significativa. $\mathrm{O}$ percentual lixiviado aumentou progressivamente à medida que se ampliava o excesso de HF em relação à quantidade estequiométrica. Praticamente todas as amostras foram dissolvidas em excesso de $50 \%$. O resíduo remanescente, branco, tem massa aproximadamente equivalente à conversão do cálcio (Tabela 1) em fluoreto, $\mathrm{CaF}_{2}$ ( $\sim 6 \mathrm{~g} \mathrm{~kg}^{-1}$ catalisador). ${ }^{48,49} \mathrm{Com}$ base nas quantidades estequiométricas calculadas de $\mathrm{HF}\left(3860 \mathrm{~mL} \mathrm{~kg}^{-1}\right.$ catalisador 1 e $3530 \mathrm{~mL} \mathrm{~kg}^{-1}$ catalisador 2) e $\mathrm{H}_{2} \mathrm{O}_{2}$ (170 mL kg-1 catalisador), para um excesso de $50 \%$ em volume de $\mathrm{HF}$ e $20 \%$ em volume de $\mathrm{H}_{2} \mathrm{O}_{2}$, a relação massa de catalisador/volume de lixiviante é de $166,83 \mathrm{~g} \mathrm{~L}^{-1}$ (catalisador 1) e 181,85 $\mathrm{g} \mathrm{L}^{-1}$ (catalisador 2). Essas relações são mais altas do que na maioria dos estudos relatados na literatura, ${ }^{9,22,37}$ que normalmente utilizam soluções ácidas mais diluídas e menores massas de amostra.

Tabela 3. Resíduo insolúvel recuperado após lixiviações com $\mathrm{HF}+\mathrm{H}_{2} \mathrm{O}_{2}$ $\left(60^{\circ} \mathrm{C}, 3 \mathrm{~h}\right)$

\begin{tabular}{lccccccc}
\hline \multirow{2}{*}{ Catalisador } & \multicolumn{6}{c}{$\%$ em excesso de HF em relação à quantidade estequiométrica } \\
\cline { 2 - 8 } & $0 \% *$ & $0 \%$ & $10 \%$ & $20 \%$ & $30 \%$ & $40 \%$ & $50 \%$ \\
\hline 1 & 99,5 & 97,0 & 92,1 & 62,6 & 14,0 & 1,2 & 0,9 \\
2 & 96,5 & 42,3 & 17,2 & 10,3 & 2,3 & 1,0 & 0,7 \\
\hline
\end{tabular}

* em ausência de $\mathrm{H}_{2} \mathrm{O}_{2}$.

Apesar do comportamento similar dos catalisadores nessas condições, nota-se que o catalisador 2 reagiu mais facilmente com a mistura $\mathrm{HF}+\mathrm{H}_{2} \mathrm{O}_{2}$. Trata-se da amostra que apresentou a maior perda de massa quando da remoção do coque (Tabela 2). Esse ponto necessita de estudos adicionais, mas uma hipótese é que o catalisador 1 continha compostos mais refratários que reagiram com mais dificuldade com HF. Para melhor esclarecer a diferença, seria preciso conhecer o histórico de cada um dos catalisadores na unidade de HDS para averiguar possíveis problemas de operação (picos de temperatura), e uma análise mais detalhada da estrutura do coque formado nas amostras.

$\mathrm{O}$ efeito da temperatura, mostrado na Tabela 4, é muito positivo no desempenho da mistura $\mathrm{HF}+\mathrm{H}_{2} \mathrm{O}_{2}$, particularmente acima de $40{ }^{\circ} \mathrm{C}$, situação já observada no processamento de catalisadores de hidrodessulfurização gastos em presença dessa mistura. ${ }^{47}$

Tabela 4. Efeito da temperatura na lixiviação ( $\mathrm{HF}$ (50\% excesso) $+\mathrm{H}_{2} \mathrm{O}_{2}$, $3 \mathrm{~h}$ ) aferido a partir da quantidade de resíduo insolúvel isolado após a reação

\begin{tabular}{lccccccc}
\hline \multirow{2}{*}{ Catalisador } & \multicolumn{7}{c}{ Temperatura, ${ }^{\circ} \mathrm{C}$} \\
\cline { 2 - 8 } & 25 & 30 & 35 & 40 & 50 & 55 & 60 \\
\hline 1 & 99,8 & 90,6 & 72,5 & 50,3 & 19,5 & 6,5 & 0,9 \\
2 & 99,0 & 87,5 & 65,1 & 39,5 & 14,4 & 4,5 & 0,7 \\
\hline
\end{tabular}

O efeito do tempo, mostrado na Tabela 5 , indica que um período de $2 \mathrm{~h}$ é suficiente para lixiviar mais de $99,5 \% \mathrm{~m} / \mathrm{m}$ da amostra pré-oxidada. Esse resultado está de conformidade com os dados da literatura. ${ }^{47}$

Tabela 5. Efeito do tempo na lixiviação (HF (50\% excesso) $+\mathrm{H}_{2} \mathrm{O}_{2}, 60{ }^{\circ} \mathrm{C}$ ) aferido a partir da quantidade de resíduo insolúvel isolado após a reação

\begin{tabular}{lccccc}
\hline \multirow{2}{*}{ Catalisador } & \multicolumn{5}{c}{ Tempo, h } \\
\cline { 2 - 6 } & 1 & 1,5 & 2 & 3 & 4 \\
\hline 1 & 72,5 & 20,3 & 1,0 & 1,0 & 0,9 \\
\hline 2 & 56,5 & 9,5 & 0,9 & 0,8 & 0,7 \\
\hline
\end{tabular}

A Tabela 6 apresenta a concentração dos elementos lixiviados considerando $50 \%$ de excesso de HF em relação à quantidade 
Tabela 6. Concentração dos elementos $\left(\mathrm{g} \mathrm{L}^{-1}\right)$ nos lixiviados $\left(\mathrm{HF}+\mathrm{H}_{2} \mathrm{O}_{2}, 60{ }^{\circ} \mathrm{C}, 2 \mathrm{~h}, 50 \% \text { excesso de } \mathrm{HF}\right)^{*}$

\begin{tabular}{lcccccccccccccc}
\hline Elemento & $\mathrm{Ni}$ & $\mathrm{Mo}$ & $\mathrm{Fe}$ & $\mathrm{Al}$ & $\mathrm{V}$ & $\mathrm{As}$ & $\mathrm{Cr}$ & $\mathrm{Mn}$ & $\mathrm{Si}$ & $\mathrm{Zn}$ & $\mathrm{Cu}$ \\
\hline Catalisador 1 & 5,2 & 23,7 & 1,9 & 46,6 & 0,1 & 0,2 & $6,9 \times 10^{-2}$ & $3,9 \times 10^{-2}$ & 4,3 & $1,0 \times 10^{-2}$ & $\mathrm{nd}$ \\
Catalisador 2 & 5,9 & 23,5 & 3,6 & 38,2 & 0,3 & 0,2 & $7,4 \times 10^{-2}$ & $4,9 \times 10^{-2}$ & 7,4 & $\mathrm{nd}$ & $8,0 \times 10^{-2}$ \\
\hline
\end{tabular}

*Cálcio não foi detectado nos lixiviados (precipitado como $\mathrm{CaF}_{2}$ ); nd = não detectado.

estequiométrica. Salvo o cálcio, que se encontra no resíduo insolúvel, e o enxofre, parcialmente eliminado como $\mathrm{SO}_{2}$ no momento da queima do coque, mais de $99,5 \% \mathrm{~m} / \mathrm{m}$ dos demais elementos foram lixiviados. Os resultados referentes ao processamento dos lixiviados se referirão aos experimentos com um excesso de $50 \%$ de $\mathrm{HF}$ em relação ao estequiométrico.

\section{Processamento do lixiviado}

\section{Separação de molibdênio e vanádio}

De acordo com os resultados da Figura 4, uma concentração de Alamina 304 a 10\% vol. em n-heptano é o ideal para a extração de mais de $99,9 \% \mathrm{~m} / \mathrm{m}$ de molibdênio em dois estágios. Esse resultado está de conformidade com os dados da literatura; ${ }^{9,43,52,53}$ no $\mathrm{pH}$ de extração $(1,8)$, a espécie $\mathrm{MoO}_{2}{ }^{2+}$ é a dominante. ${ }^{56} \mathrm{O}$ vanádio foi extraído $(>99,9 \% \mathrm{~m} / \mathrm{m})$ pelo extratante, resultado igualmente coerente com a literatura, ${ }^{43,53}$ devendo-se levar ainda em conta que a concentração de vanádio é da ordem de 100 vezes inferior à do molibdênio (Tabela 1). É de se notar que o comportamento da extração dos dois elementos em meio fluoreto é comparável àquele observado em meio sulfúrico..$^{43,44,53}$

Foi possível extrair os dois elementos em um só estágio empregando uma solução de Alamina 304 a 20\% vol. Contudo, houve formação de uma terceira fase, que foi somente eliminada com a adição de 1-decanol (modificador de fase), ${ }^{44,53}$ aumentado a solubilidade do produto de extração no diluente.

A reextração dos dois elementos para a fase aquosa foi bemsucedida (>99,5\% m/m) com solução de amônia $5 \mathrm{~mol} \mathrm{~L}^{-1}$ (Figura 4). Concentrações acima de $6 \mathrm{~mol} \mathrm{~L}^{-1}$ levaram à emulsificação do sistema. Após ajustar o pH da solução amoniacal em 7, o sólido formado, branco, continha apenas vanádio, de acordo com os testes qualitativos para Mo e V. ${ }^{48,49}$ Trata-se do metavanadato de amônio, $\mathrm{NH}_{4} \mathrm{VO}_{3}$. A pequena quantidade de massa obtida (da ordem de 2,2 $\mathrm{g} \mathrm{NH}_{4} \mathrm{VO}_{3} \mathrm{~kg}^{-1}$ catalisador 1 e $6,8 \mathrm{~g} \mathrm{~kg}^{-1}$ para o catalisador 2) se deve ao baixo teor de vanádio nas amostras (Tabela 1) e lixiviados (Tabela 5). Uma vantagem da amônia aquosa é evitar a introdução de cátions e ânions de difícil remoção. $\mathrm{O}$ heptamolibdato de amônio $\left[\left(\mathrm{NH}_{4}\right)_{6} \mathrm{Mo}_{7} \mathrm{O}_{24} \cdot 4 \mathrm{H}_{2} \mathrm{O}\right]$ pode ser obtido por evaporação da solução

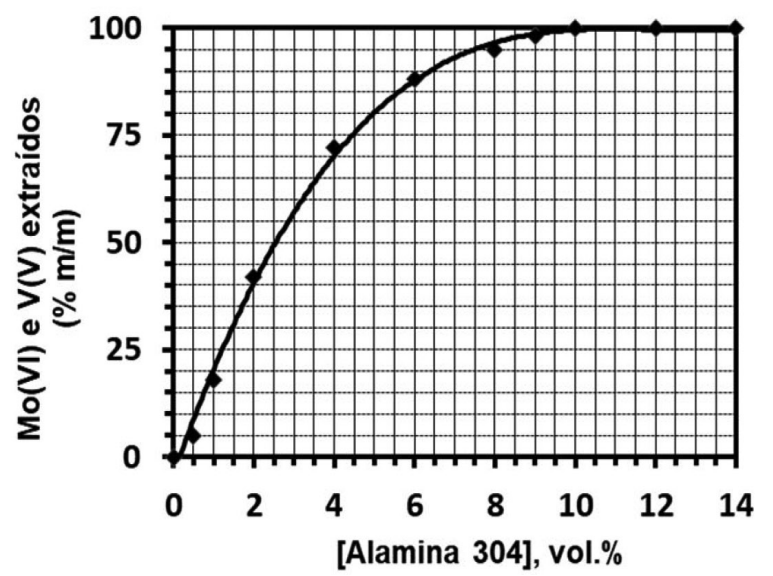

aquosa após a precipitação do vanádio. A calcinação desse sal a $360{ }^{\circ} \mathrm{C}$ fornece o óxido $\mathrm{MoO}_{3} \cdot{ }^{53}$

\section{Separação de alumínio e ferro}

$\mathrm{O}$ difratograma de raios $\mathrm{X}$ do sólido branco obtido em $\mathrm{pH} 4$ corresponde a $\mathrm{Na}_{3} \mathrm{AlF}_{6}$ (Figura 5), de conformidade com a ficha padrão ICDD $\mathrm{n}^{\circ}$ 25-0772. Os dados de fluorescência de raios $X$ indicam a seguinte composição química média: $32,6 \% \mathrm{~m} / \mathrm{m}$ de $\mathrm{Na}$, $12,6 \% \mathrm{~m} / \mathrm{m}$ de $\mathrm{Al}, 54,0 \% \mathrm{~m} / \mathrm{m}$ de $\mathrm{F}$ e $0,8 \% \mathrm{~m} / \mathrm{m}$ de Fe. Esses dados se aproximam dos valores teóricos ${ }^{49}$ para a criolita sintética $(32,86 \%$ $\mathrm{m} / \mathrm{m}$ de $\mathrm{Na}, 12,86 \% \mathrm{~m} / \mathrm{m}$ de Al e $54,28 \% \mathrm{~m} / \mathrm{m}$ de F, $\mathrm{K}_{\mathrm{ps}} 4 \times 10^{-10}$ ). O ferro aparece com um percentual baixo no sólido visto que seu teor nos catalisadores gastos é de 10 a 30 vezes menor que o do alumínio (Tabela 1). Os demais elementos presentes nos catalisadores não se acham presentes em quantidades detectáveis pelo método analítico. A massa combinada de $\mathrm{Na}_{3} \mathrm{AlF}_{6}+\mathrm{Na}_{3} \mathrm{FeF}_{6}$ obtida (Tabela 7) variou de $\sim 1870 \mathrm{~g} \mathrm{~kg}^{-1}$ catalisador $2 \mathrm{a} \sim 2230 \mathrm{~g} \mathrm{~kg}^{-1}$ catalisador 1 , reflexo dos teores de alumínio e ferro nessas amostras (Tabela 1). Com base nos dados da Tabela 1 e nos dados de FRX dos sólidos, mais de 99,5\% $\mathrm{m} / \mathrm{m}$ dos dois elementos foram recuperados no precipitado em $\mathrm{pH} 4$. A precipitação do alumínio nesse $\mathrm{pH}$ em meio de fluoreto já foi relatada na literatura como muito efetiva para alumínio (e ferro). ${ }^{45,47,54,57}$

Um mérito de isolar o alumínio e o ferro como $\mathrm{Na}_{3} \mathrm{AlF}_{6} / \mathrm{Na}_{3} \mathrm{FeF}_{6}$ em pH 4 é evitar a interferência do $\mathrm{Fe}(\mathrm{III})$ e do $\mathrm{Al}(\mathrm{III})$ na extração do $\mathrm{Mo}(\mathrm{VI})$ e do $\mathrm{V}(\mathrm{V})$ pela Alamina $304,{ }^{52,53}$ e ainda possibilitar o isolamento do níquel e do fluoreto de sódio ao final do processo livres de contaminação pelos mesmos. ${ }^{47,54}$

\section{Separação do níquel - extração por solvente}

Segundo os dados da Figura 6, Ni(II) foi extraído $(>99,5 \% \mathrm{~m} / \mathrm{m})$ em um estágio com uma concentração do extratante em n-heptano igual a 10 vol.\%. A reextração do $\mathrm{Ni}(\mathrm{II})$ da fase orgânica em um único estágio foi possível usando uma solução $1 \mathrm{~mol} \mathrm{~L}^{-1} \mathrm{H}_{2} \mathrm{SO}_{4}$ (Figura 6).

Esses resultados se acham de conformidade com o desempenho relatado na literatura em meio fluoreto e sulfúrico. ${ }^{54}$ Contudo, outros elementos presentes no lixiviado também foram extraídos: $\mathrm{Zn}(\mathrm{II})$, $\mathrm{Cu}(\mathrm{II}), \mathrm{Mn}(\mathrm{II})$ e $\mathrm{Cr}(\mathrm{III})$, os quais são extraídos por D2EHPA em pH mais ácido do que o $\mathrm{Ni}(\mathrm{II}),{ }^{58}$ inclusive os dois primeiros também em

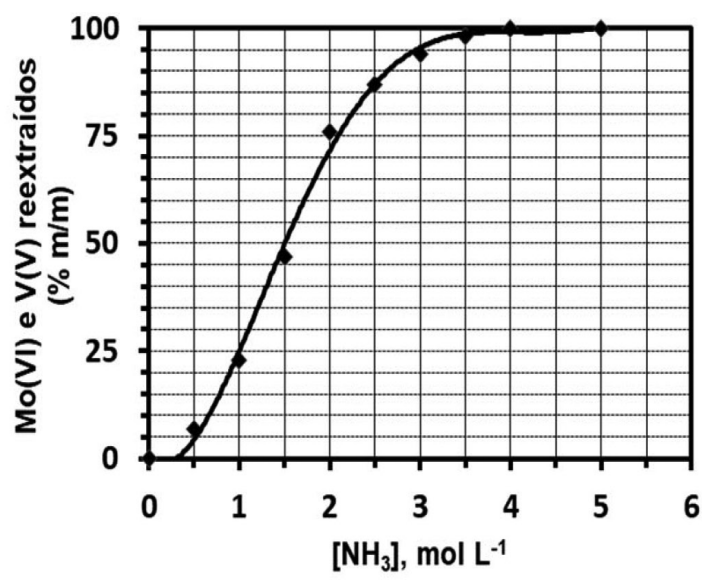

Figura 4. Extração do Mo(VI) e do V(V) em função da concentração de Alamina 304 em n-heptano $\left(25{ }^{\circ} \mathrm{C}\right.$, A/O = 1 v/v, pH 1,8 , dois estágios, esquerda), e reextração com solução aquosa de amônia (direita) 


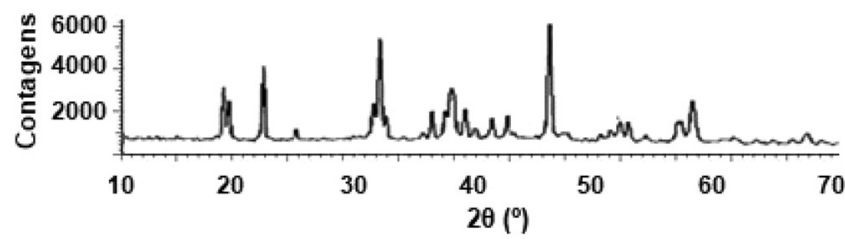

Figura 5. Difratograma do sólido obtido após precipitação do ferro e do alumínio em $\mathrm{pH}$ 4. Os picos representam hexafluoroaluminato de sódio $\left(\mathrm{Na}_{3} \mathrm{AlF}_{6}\right)$
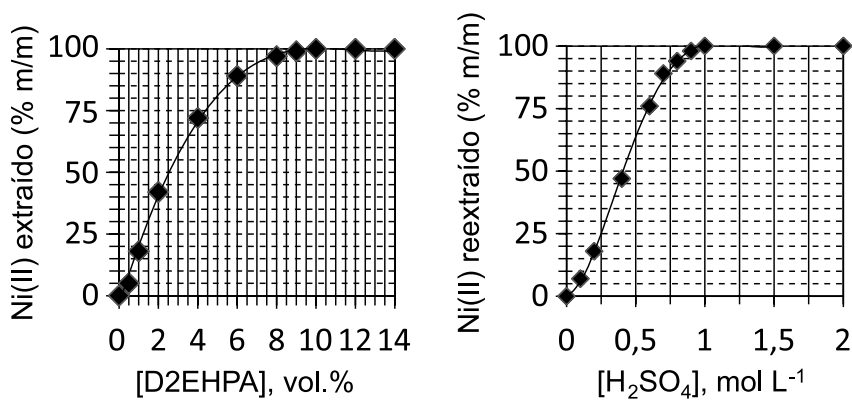

Figura 6. Extração de Ni(II) com D2EHPA em pH 6 (esquerda), e reextração com solução aquosa de ácido sulfúrico (direita)

meio fluoreto. ${ }^{54}$ Após a reextração da fase orgânica carregada com $\mathrm{H}_{2} \mathrm{SO}_{4} 1 \mathrm{~mol} \mathrm{~L}^{-1}$, os dados de AAS indicam que $\mathrm{Ni}(\mathrm{II})$ apresenta uma proporção em massa relativa de $98 \%$, seguido de $\mathrm{Cr}$ (III) $(0,9-1,0 \%)$, $\mathrm{Mn}(\mathrm{II})(0,6-0,7 \%), \mathrm{Cu}(\mathrm{II})(0,9 \%$, catalisador 2$)$ e $\mathrm{Zn}(\mathrm{II})(0,2 \%$, catalisador 1$)$.

\section{Separação do níquel - precipitação}

Em comparação ao método de extração por solvente em pH 6, a precipitação em $\mathrm{pH} 8$ foi menos satisfatória. Embora todo o níquel tenha precipitado (ele não foi detectado no filtrado), além dos elementos coextraídos por D2EHPA, o precipitado contém fósforo, arsênio, cálcio, silício e ainda quantidades consideráveis de enxofre, conforme exemplificado pelos dados de FRX obtidos para o catalisador $2: 50,5 \% \mathrm{~m} / \mathrm{m}$ de $\mathrm{Ni} ; 28,7 \% \mathrm{~m} / \mathrm{m}$ de $\mathrm{P} ; 13,0 \% \mathrm{~m} / \mathrm{m}$ de $\mathrm{S}$; $4,4 \% \mathrm{~m} / \mathrm{m}$ de Ca; $2,2 \% \mathrm{~m} / \mathrm{m}$ de As; $0,5 \% \mathrm{~m} / \mathrm{m}$ de $\mathrm{Cr} ; 0,2 \% \mathrm{~m} / \mathrm{m}$ de $\mathrm{Mn} ; 0,2 \% \mathrm{~m} / \mathrm{m}$ de $\mathrm{Cu} ; 0,2 \% \mathrm{~m} / \mathrm{m}$ de $\mathrm{Si}$. O níquel corresponde a pouco mais da metade dos elementos precipitados. Esse resultado reflete a dificuldade em se obter, por precipitação, um sólido com grau de pureza elevado a partir de uma mistura complexa de analitos reativos. ${ }^{36}$ de $\mathrm{Na}, 47,4 \% \mathrm{~m} / \mathrm{m}$ de $\mathrm{F}$ e $2,1 \% \mathrm{~m} / \mathrm{m}$ de Si (catalisador 2 ). Nenhum outro elemento foi detectado por fluorescência, o que se deve ao carreamento para o precipitado contendo níquel das impurezas presentes em solução no momento da neutralização a pH 8, ou na formação do precipitado após ajuste do $\mathrm{pH}$ em 9 após a extração do $\mathrm{Ni}(\mathrm{II})$ por D2EHPA.

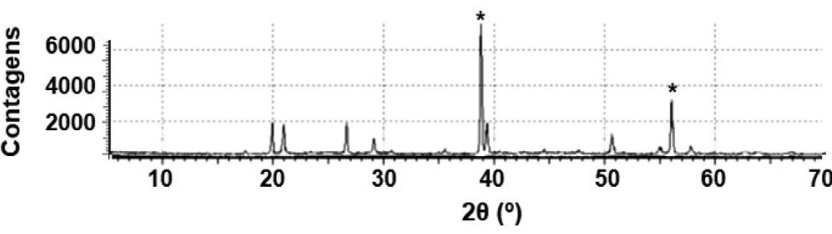

Figura 7. Difratograma do sólido obtido após evaporação cuidadosa da solução final à secura. Os picos marcados com * representam fluoreto de sódio, $\mathrm{NaF}$; os demais correspondem ao hexafluorossilicato de sódio, $\mathrm{Na}_{2} \mathrm{SiF}_{6}$

A massa de $\mathrm{NaF}+\mathrm{Na}_{2} \mathrm{SiF}_{6}$ obtida foi da ordem de $2100 \mathrm{~g} \mathrm{~kg}^{-1}$ para ambos os catalisadores (Tabela 7). Com base na composição obtida por FRX, o sal $\mathrm{Na}_{2} \mathrm{SiF}_{6}$ corresponde a pouco mais de $8 \%$ da massa total (catalisador 1) e a $14 \% \mathrm{~m} / \mathrm{m}$ no caso do catalisador 2 . Pelo teor de silício nas amostras em exame (Tabela 1), conclui-se que mais de $99 \% \mathrm{~m} / \mathrm{m}$ desse elemento está presente nesse sólido.

Geralmente o silício fica no resíduo insolúvel das lixiviações ácidas com ácidos inorgânicos $\left(\mathrm{H}_{2} \mathrm{SO}_{4}, \mathrm{HCl}\right.$ etc.) por não ser reativo com eles, mas seu mascaramento com íons fluoreto fez com que ele não interferisse nas etapas de separaçãa $0^{54}$ que precederam à sua recuperação.

Não há necessidade de separar $\mathrm{NaF}_{\text {de }} \mathrm{Na}_{2} \mathrm{SiF}_{6}$ visto que ambos são usados em processos de fluoretação da água, ${ }^{59}$ como preservativo da madeira ${ }^{60,61}$ e como fluxo em metalurgia. ${ }^{62}$

\section{Balanço de massa para o íon fluoreto}

Dado que o ácido fluorídrico é um reagente tóxico e causador de impactos ambientais, todo processo que o utiliza deve ser monitorado com vistas a evitar ou minimizar perdas de fluoreto para o ambiente (emissões, efluentes). A conversão do íon fluoreto em compostos de valor comercial é uma estratégia para valorizá-lo como insumo.

$\mathrm{O}$ ponto de partida é a mistura $\mathrm{HF}+\mathrm{H}_{2} \mathrm{O}_{2}$, a qual contém todo o fluoreto adicionado ao meio reacional. $\mathrm{O}$ íon fluoreto se acha presente nos seguintes produtos finais: (a) no precipitado de $\mathrm{CaF}_{2}$ isolado ao

\section{Recuperação do fluoreto de sódio}

O difratograma da Figura 7 mostra picos característicos do fluoreto de sódio (ficha padrão ICDD no $36-1455$ ) e do hexafluorossilicato de sódio (ficha padrão ICDD n ${ }^{\circ} 33-1280$ ). Outro dado que confirma essa premissa é a análise por fluorescência de raios x: $52,3 \% \mathrm{~m} / \mathrm{m}$ de $\mathrm{Na}, 46,5 \% \mathrm{~m} / \mathrm{m}$ de F e $1,2 \% \mathrm{~m} / \mathrm{m}$ de Si (catalisador 1 ); $50,5 \% \mathrm{~m} / \mathrm{m}$

Tabela 7. Distribuição do íon fluoreto em seus produtos finais (base: $100 \mathrm{~g}$ de catalisador)

\begin{tabular}{|c|c|c|c|}
\hline Produto/Solução de lixívia & Mass obtida $(\mathrm{g})$ & Massa de $\mathrm{F}^{-}(\mathrm{g})$ & Proporção relativa $(\% \mathrm{~m} / \mathrm{m})$ \\
\hline 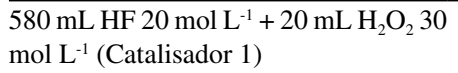 & - & 220,4 & $100 \%$ \\
\hline 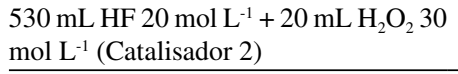 & - & 201,4 & $100 \%$ \\
\hline $\mathrm{CaF}_{2}$ (cat. 1) & 0,60 & 0,29 & 0,13 \\
\hline $\mathrm{CaF}_{2}$ (cat. 2) & 0,62 & 0,30 & 0,15 \\
\hline $\mathrm{Na}_{3} \mathrm{AlF}_{6}+\mathrm{Na}_{3} \mathrm{FeF}_{6}$ (cat. 1) & 222,6 & 120,5 & 54,69 \\
\hline $\mathrm{Na}_{3} \mathrm{AlF}_{6}+\mathrm{Na}_{3} \mathrm{FeF}_{6}$ (cat. 2) & 187,1 & 101,0 & 50,14 \\
\hline $\mathrm{Na}_{2} \mathrm{SiF}_{6}+\mathrm{NaF}$ (cat. 1) & 213,4 & 99,3 & 45,04 \\
\hline $\mathrm{Na}_{2} \mathrm{SiF}_{6}+\mathrm{NaF}$ (cat. 2) & 210,7 & 99,9 & 49,60 \\
\hline Perdas (cat. 1) & - & 0,3 & 0,14 \\
\hline Perdas (cat. 2) & - & 0,2 & 0,10 \\
\hline
\end{tabular}


término da lixiviação; (b) nos precipitados contendo $\mathrm{Al}$ e $\mathrm{Fe}\left(\mathrm{Na}_{3} \mathrm{AlF}_{6}\right.$ e $\left.\mathrm{Na}_{3} \mathrm{FeF}_{6}\right)$; (c) no sólido final $\left(\mathrm{NaF}+\mathrm{Na}_{2} \mathrm{SiF}_{6}\right)$. Três fontes em potencial de perdas de íons fluoreto foram identificadas: (a) como HF na fase gasosa durante a lixiviação; (b) durante a manipulação das soluções; (c) durante a extração por solvente de Mo(VI), V(V) e Ni(II).

A mistura usada para o balanço de massa é a que contém $50 \%$ em excesso de HF em relação ao estequiométrico. Os dados são apresentados na Tabela 7. A distribuição do fluoreto nos diversos produtos seguiu estritamente as previsões, sendo a maior parte do íon fluoreto encontrada na mistura $\mathrm{Na}_{3} \mathrm{AlF}_{6}+\mathrm{Na}_{3} \mathrm{FeF}_{6}$. As perdas foram baixas (da ordem de $0,1 \% \mathrm{~m} / \mathrm{m}$ ), sendo atribuídas à baixa temperatura de lixiviação, $60{ }^{\circ} \mathrm{C}$, e à recuperação do sólido final em meio alcalino nessa mesma temperatura, minimizando perdas de $\mathrm{HF}$ durante a evaporação.

\section{CONCLUSÕES}

O processamento de catalisadores submetidos a condições drásticas de ultra-deep HDS exigiu um excesso considerável de ácido fluorídrico na presença de peróxido de hidrogênio, mas foi obtida uma dissolução quase total em condições moderadas $\left(2 \mathrm{~h}\right.$ a $\left.60^{\circ} \mathrm{C}\right)$, sendo o resíduo insolúvel composto basicamente por fluoreto de cálcio, $\mathrm{CaF}_{2}$. Como pré-requisito, a oxidação prévia dos catalisadores é de extrema importância para que se obtenha um bom processamento em meio ácido. A taxa de aquecimento deve ser muito lenta, da ordem de $0,5^{\circ} \mathrm{C}$ por minuto, com o intuito de reduzir as chances de ignição do coque, o que levaria a uma sensível perda de rendimento na lixiviação, conforme assinalado na literatura.

O fracionamento do lixiviado fluorídrico foi possível mediante uma combinação de técnicas de extração por solvente (molibdênio, vanádio) em $\mathrm{pH}$ ácido $(<2)$, precipitação seletiva (alumínio, ferro) em $\mathrm{pH} \sim 4$ e isolamento de uma fração contendo níquel por precipitação mediante neutralização da solução, ou por extração por solvente em meio levemente ácido. Particularmente no método de precipitação, o níquel carrega consigo a maioria dos elementos presentes no lixiviado, o que exige etapas posteriores para obter esse elemento com pureza elevada. O desempenho da extração por solvente em meio fluoreto para Mo, $\mathrm{V}$ e Ni acompanha os resultados da literatura para outros meios ácidos. A precipitação do $\mathrm{Al}$ e do $\mathrm{Fe}$ em $\mathrm{pH} \sim 4$ evitou a interferência desses elementos nos processos de extração por solvente, na precipitação do níquel, e na cristalização do produto final.

O produto final, consistindo em uma mistura de fluoreto de sódio e hexafluossilicato de sódio, tem valor comercial, fato relevante na medida em que é grandemente reduzida a geração de resíduos finais. As moderadas condições experimentais (notadamente as temperaturas de lixiviação e de evaporação da solução final) minimizaram sobremodo as perdas de fluoreto para o ambiente.

\section{AGRADECIMENTOS}

C. L. Quintanilha agradece à Agência Nacional de Petróleo, Gás Natural e Biocombustíveis (ANP) a concessão de bolsa de iniciação científica. Os autores agradecem ao CNPq pelo auxílio financeiro. Ao CENPES/Petrobras pela cessão dos catalisadores e dados de análise elementar e de enxofre.

\section{REFERÊNCIAS}

1. Rodríguez, E.; Félix, G.; Anchyeta, J.; Trejo, F.; Fuel 2018, 225, 118; Marafi, M.; Stanislaus, A. M.; Resour., Conserv. Recycl. 2008, 53, 1.

2. Vogelaar, B. M.; Eijsbouts, S.; Bergwerff, J. A.; Heiszwolf, J. J.; Catal. Today 2010, 154, 256.
3. Leyvaa, C.; Ancheyta, J.; Marieyb, L.; Travertb, A.; Maugé, F.; Catal. Today 2014, 220-222, 89.

4. Kohli, K.; Prajapati, R.; Maity, S. K.; Sal, M.; Sharma, B. K.; Fuel 2019, 235, 437.

5. Torres-Mancera, P.; Anchyeta, J.; Martínez, J.; Fuel 2018, 234, 326.

6. Al-Zubaidi, I.; Yang, C.; EJERS 2020, 5, 938.

7. Wang, L.; Chao, L.; Qu, W.; Xu, S.; Zhang, L.; Peng, J.; Ye, X.; Ultrason. Sonochem. 2018, 49, 24.

8. Shen, W.; Li, T.; Chen, J.; Procedia Environ. Sci. 2021, 16, 253; Afonso, J. C.; Aguiar, R. M.; Silva, G. C.; Stud. Surf. Sci. Catal. 2001, 139, 165.

9. Valverde Jr., I. M.; Paulino, J. F.; Afonso, J. C.; J. Hazard. Mater. 2008, 160, 310; Moreau, C.; Joffre, J.; Saenz, C.; Afonso, J. C.; Portefaix, J. L.; J. Mol. Catal. A: Chem. 2000, 161, 141.

10. Imam, D. M.; El-Nadi, Y. A.; Hydrometallurgy 2018, 180, 172.

11. Rana, M. S.; Ancheyta, J.; Sahoo, S. K.; Rayo, P.; Catal. Today 2014 220-222, 97.

12. Yang, Y.; Shengming, X.; Li, Z.; Wang, J.; Zhao, Z.; Xu, Z.; J. Hazard. Mater. 2016, 318, 723.

13. Koh, J. H.; Lee, J. J.; Kim, H.; Cho, A.; Moon, S. H.; Appl. Catal., B 2009, 86, 176.

14. Guichard, B.; Auberger, M. R.; Devers, E.; Legens, C.; Raybaud, P.; Catal. Today 2008, 130, 97.

15. Gao, Q.; Ofosu, T. N. K.; Ma, S; Komvokis, V. G.; Williams, C. T.; Segawa, K.; Catal. Today 2011, 164, 538.

16. Guichard, B.; Roy-Auberger, M.; Devers, E.; Rebours, B.; Quoineaud, A. A.; Digne, M.; Appl. Catal., A 2009, 367, 1.

17. Ramirez, S.; Leyva, C.; Ancheyta, J.; Centeno, G.; Fuel 2009, 88, 2311.

18. Callejas, M. A.; Martınez, M. T.; Blasco, T.; Sastre, E.; Appl. Catal., A 2001, 218,181

19. Maity, S. K.; Blanco, E.; Ancheyta, J.; Alonso, F.; Fukuyama, H.; Fuel 2012, 100, 17.

20. Torres-Mancera, P.; Rayo, P.; Ancheyta, J.; Marroquín, G.; Centeno, G.; Alonso, F.; Catal. Today 2014, 220-222, 153.

21. Akcil, A.; Vegliò, F.; Ferela, F.; Okudan, M. D.; Tuncuk, A. Waste Manage. 2015, 45, 420.

22. Yue, Y.; Tiantian, C.; Yong, X.; GuoYong, H.; Wenqiang, W.; Qi, L.; Shengming, X.; Waste Manage. 2018, 78, 595.

23. Gawel, I.; Bociarska, D.; Biskupski, P.; Appl. Catal. A: Gen. 2005, 295 , 89.

24. Marafi, M.; Al-Sheeha, H.; Al-Omani, S.; Al-Barood, A.; Fuel Process. Technol. 2009, 90, 264.

25. Wood, J.; Gladden, L. F.; Appl. Catal., A 2003, 249, 241.

26. Maity, S. K.; Ancheyta, J.; Alonso, F.; Rayo, P.; Fuel Process. Technol. 2013, 106, 453.

27. Duarte, I.; Garzón, L.; Medrano, V. G. B.; Catal. Today 2019, 338, 100.

28. Afonso, J. C.; Aranda, D. A. G.; Schmal, M.; Fréty, R.; Fuel Process. Technol. 1995, 42, 3 .

29. Afonso, J. C.; Aranda, D. A. G.; Schmal, M.; Fréty, R.; Fuel Process. Technol. 1997, 50, 35 .

30. Guichard, B.; Roy-Auberger, M.; Devers, E.; Pichon, C.; Legens, C.; Appl. Catal., A 2009, 367, 9.

31. Stanislaus, A.; Marafi, A.; Rana, M. S.; Catal. Today 2010, 153, 1.

32. Afonso, J. C.; Silva, G. C.; Aguiar, R. M.; Stud. Surf. Sci. Catal. 2001, 139,165

33. Pereira, A. L. S.; Silva, C. N.; Mantovano, J. L.; Afonso, J. C.; Quim. Nova 2011, 34, 145.

34. Ferreira, P. F.; Sérvulo, E. F. C.; Costa, A. C. A; Ferreira, D. M.; Godoy, M. L. D. P.; Oliveira, F. J. S.; Braz. J. Chem. Eng. 2017, 34, 119; Afonso, J. C.; da Silva, N.; Salvato, G. N.; Busnardo, R. G.; Quim. Nova 2006, 29, 856.

35. Marafi, M.; Rana, M. S.; Int. J. Energy Environ. Eng. 2017, 11, 901.

36. Le, M. N.; Lee, M. S.; Miner. Process. Extr. Metall. Rev. 2021, 42, 335. 
37. Koizumi, N.; Urabe, Y.; Inamura, K.; Itoh, T; Yamada, M.; Catal. Today 2005, 106, 211.

38. Pessanha, T. M.; Quintanilha, C. L.; Silva, C. N.; Afonso, J. C.; Quim. Nova 2019, 42, 397.

39. Yaras, A.; Arslanoglu, H.; Sep. Sci. Technol. 2020, 55, 2037.

40. Wang, W.; Zhang, L.; Han, Y.; Zhang, Y.; Liu, X.; Xu, S.; J. Clean. Prod. 2019, 232, 266.

41. Zhang, D.; Liu, Y.; Hu, Q.; Ke, X.; Yuan, S.; Liu, S.; Ji, X.; Hu, J.; J. Clean. Prod. 2020, 252, 119763.

42. Marafi, M.; Rana, M. S.; J. Environ. Sci. Health, Part A: Environ. Sci. Eng. Toxic Hazard. Subst. Control 2018, 53, 951.

43. Sun, X.; Liu, Z.; Yang, W.; Gu, S.; Yu, J.; Environ. Prog. Sustainable Energy 2019, 38, 13169.

44. Nagib, S.; Hameeda, R. S.; Green Chem. Lett. Rev. 2017, 10, 210.

45. Pinheiro, A. A. S.; Lima, T. S.; Campos, P. C.; Afonso, J. C.; Hydrometallurgy 2004, 74, 77.

46. Marchala, C.; Uzioa, D.; Merdrignaca, I.; Barreb, L.; Geantet, C.; Appl. Catal., A 2012, 411-412, 35.

47. Lima, T. S.; Campos, P. C.; Afonso, J. C.; Hydrometallurgy 2005, 80, 211.

48. Feigl, F.; Spot Tests in Inorganic Analysis, Elsevier: Amsterdam, 1958, chap. 3.

49. Lurie, J.; Handbook of Analytical Chemistry, $3^{\text {rd }}$ ed., Mir: Moscow, 1978, chap. 3, 6 and 10 .

50. Oliveira, M. C.; Nogueira, R. F. P.; Gomes Neto, J. A.; Jardim, W. F.; Rohwedder, J. J. R.; Quim. Nova 2001, 24, 188.
51. Tjtko, K. H.; Gras, D.; Molybdenum. Gmelin Handbook of Inorganic Chemistry, Springer-Verlag: Berlin-Heidelberg GmbH, 1989, p. 132.

52. Gerhardt, N. I.; Palant, A. A.; Petrova, V. A.; Tagirov, R. K.; Hydrometallurgy 2001, 60, 1.

53. Zhu, Z.; Cheng, C. Y.; A review of uranium solvent extraction: its present status and future trends. The Commonwealth Scientific and Industrial Research Organisation: Canberra, 2011, p. 22.

54. Silva, W. C.; Corrêa, R. S.; Silva, C. S. M.; Afonso, J. C.; Silva, R. S.; Vianna, C. A.; Mantovano, J. L.; Waste Manage. 2018, 78, 781.

55. Guilhen, S. N.; Cotrim, M. E. B.; Sakata, S. K.; Scapin, M. A.; REM: Int. Eng. J. 2019, 72, 609.

56. Saberyjan, K.; Maragheh, M. G.; Ashtari, P.; Alamdari, S. K.; Miner. Eng. 2003, 16, 391.

57. Kumar, M.; Babu, M. N.; Mankhand, T. R.; Pandey, B. D.; Hydrometallurgy 2020, 104, 304.

58. Ritcey, G. M.; Ashbrook, A. W.; Principles and Applications to Process Metallurgy (Part I) Elsevier: New York, 1984.

59. Machalinski, B.; Baskiewicz-Masiuk, M.; Sadowska, B.; Machalinska, A.; Marchlewicz, M.; Wiszniewska, B.; Stecewicza, I.; Fluoride 2003, $36,231$.

60. Mai, C.; Militz, H.; Wood Sci. Technol. 2004, 37, 339.

61. Pan, C.; Ruan, G.; Chen, H.; Zhang, D.; Eur. J. Wood Prod. 2015, 73, 97.

62. Luz, A. B.; Sampaio, J. A.; Almeida S. L. M.; Tratamento de Minérios, $4^{\text {a }}$ ed., Centro de Tecnologia Mineral: Rio de Janeiro, 2004, cap. 14 e 22. 